\title{
Identifying Measures for Assessing the Readiness of Handheld Application Usage
}

\author{
Amalina A. F. Fadzlah
}

\begin{abstract}
This study was designed to identify measures with which to assess the readiness of handheld application usage, aiming to achieve four major objectives: 1) identify measures for the assessment of the readiness of handheld application usage, 2) analyze the association and relationship between these measures towards assessing the readiness of handheld application usage, 3) rank the readiness measures in order to assess the readiness of handheld application usage, and 4) construct a conceptual framework within which to structure the readiness measures and to assess the readiness of handheld application usage. A total of thirteen readiness measures (comprising ten readiness metrics and three readiness attributes) were identified as being associated with assessing the readiness of handheld application usage. These measures are valuable as an alternative method or technique with which to assess the readiness of handheld application usage.
\end{abstract}

Index Terms-Application, assessment, handheld, readiness, measures.

\section{INTRODUCTION}

The latest technological advance to radically alter perceptions of computing was the emergence of handheld devices, considered to be at the forefront of the fourth wave in the evolution of computing technology [1]-[5]. In the past few years, a gigantic explosion of interest has taken place regarding the use of these devices in various fields for various purposes among various people [6], [7]. Potential uses for handheld devices are thus burgeoning in number and very soon will supplant conventional computing technology such as desktop and laptop devices [8]-[10].

The era of handheld computing technology began when the movement of people became crucial. Past studies have identified the unique characteristics of handheld devices that make them extremely popular and have demonstrated their rapid adoption among computing technology users [11]-[14]. However, these handheld devices have been criticized as some of the most excessively hyped new computing products of all time [15], [16]. As the devices are by nature small in size, in order to support the new idea of anyone, anytime and anywhere handheld computing technology, the challenge of application readiness soon presented itself [17], [18].

The problem of application readiness and acceptance is today more complex than ever. Generally, readiness is described as the state of having been made ready or prepared for use or action. More specifically, the term readiness from a

Manuscript received September 15, 2013; revised March 14, 2014. This work was supported by the Department of Computer Science, Faculty of Defense Science and Technology, Universiti Pertahanan Nasional Malaysia.

A. F. A. Fadzlah is with the Department of Computer Science, Faculty of Defense Science and Technology, Universiti Pertahanan Nasional Malaysia, 57000 Kuala Lumpur, Malaysia (e-mail: amalina.farhi@upnm.edu.my). software quality point of view can be defined as the state of being completely and clearly developed and prepared to meet user expectations and requirements [19], [20]. Meanwhile, from the perspective of useful and usable software, readiness can also be defined as the degree to which software has been made ready or prepared for use in terms of reflecting the real world object or event described, based on user needs and requirements.

Many studies have been conducted over the past few years which mention the importance of readiness factors in assuring both software quality and usability [21]-[24]. Some researchers also classify readiness as an essential characteristic with which to evaluate and assess the quality and usability of software [25]-[28]. However, within the domain of handheld application usage, few activities have been proposed which explore the concept of readiness in terms of adapting user interfaces to the small display of handhelds [29]-[32].

Although these previous studies provide a lot of useful information regarding understanding software as well as its user interface readiness, a general lack of effort has been made to employ readiness measures when assessing handheld application usage. There thus exists a strong imperative to initiate new research aimed at identifying measures with which to assess the readiness of handheld application usage. The results presented not only reveal the readiness factors of handheld applications for users, but also provide a better understanding of the relationship between these factors. In addition, the findings can be employed as a concrete evaluation technique with which to assess the readiness of handheld application usage.

\section{MATERIALS AND METHODS}

This study was designed to achieve four major objectives: identify suitable measures with which to assess the readiness of handheld application usage, analyze the relationship between these measures towards assessing the readiness of handheld application usage, rank these readiness measures in order to assess the readiness of handheld application usage, and finally construct a conceptual framework within which to structure the readiness measures in order to assess the readiness of handheld application usage.

\section{A. Identifying the Readiness Assessment Measures}

In order to identify suitable measures with which to assess the readiness of handheld application usage, a questionnaire survey entitled 'Investigating the Readiness Measures for Assessing the Handheld Application Usage' was developed. The purpose of conducting this survey was to elicit responses from target respondents in order to detect which measures needed to be included and which needed to be excluded from 
the assessment process.

The questionnaire was used to gather information from users regarding their experience and perception of handheld application use, and comprised two sections. The first of these sections commanded respondents to indicate their level of agreement with ten statements, with the second inviting them to rank their choices by order of preference.

A pilot study was also conducted in order to confirm the validity and reliability of the results, as well as to obtain a greater understanding towards the most suitable questionnaire construction. Following this pilot study, a total of two hundred and nineteen respondents among the handheld application users were questioned, for which the response rate was approximately seventy-seven percent. This percentage was considered satisfactory given that it exceeded the research minimum acceptable level of fifty percent plus one.

\section{B. Analyzing Readiness Measure Association and Relationships}

Data collected from the final questionnaire were entered into the Statistical Package for the Social Sciences (SPSS) software program for analysis, as well as to subsequently classify the readiness measures into a hierarchical structure of metrics and attributes towards assessing the readiness of handheld application usage.

This process involved two evaluation tests: Pearson's Chi-square test and Spearman's Rho test. Whereas the former was conducted to measure the amount of association between two different readiness measures in two different hierarchy levels, the latter was carried out to determine the relationship strength between the two measures in order to assess the overall readiness of handheld application usage.

\section{Ranking the Readiness Measures}

Each of the readiness measures were ranked from highest to lowest priority based on the results of the association and relationship analyses, with the ultimate aim of assessing the readiness of handheld application usage. The procedure for ranking the readiness measures involved scoring the analysis results separately, with the highest value labeled 1 , the second highest 2 , and so on.

The points for each association and relationship scores were then averaged and assigned to the rank order of the readiness measures. The readiness measure with the lowest mean point total was thus considered the most important and that with the highest total the least important.

\section{Constructing a Conceptual Readiness Framework}

A conceptual framework specifically aimed at the assessment of handheld application usage readiness was developed by mapping the readiness measures based on their respective hierarchy levels. The end-product was a hierarchical conceptual framework here entitled the Readiness Measurement Framework (RMF).

\section{RESUlTS AND DISCUSSION}

\section{A. Identification of Readiness Measures}

From a review of previous studies, a total of ten readiness metrics (measurable readiness data expressed in units) were identified as contributing towards the assessment of handheld application usage readiness. The definition of each readiness metric is presented below (Table I).

TABLE I: DESCRIPTION OF READINESS METRICS

\begin{tabular}{ll}
\hline \hline Metric & Description \\
\hline Answers Supplied & Number of answers supplied correctly \\
Examples Provided & Number of examples provided correctly \\
Information Memorized & Amount of information memorized correctly \\
Layouts Recognized & Number of layouts recognized correctly \\
Meanings Understood & Number of meanings understood correctly \\
Problems Solved & Number of problems solved correctly \\
Questions Given & Number of questions given correctly \\
Reasons Explained & Number of reasons explained correctly \\
Representations Recalled & Number of representations recalled correctly \\
Skills Integrated & Number of skills integrated correctly \\
\hline \hline
\end{tabular}

These ten measures were classified into three main readiness attributes: Individual Interpretation, Interface Acceptance, and Knowledge Acquisition. The definition of each attribute is displayed below (Table II).

TABLE II: DESCRIPTION OF READINESS ATTRIBUTES

\begin{tabular}{lll}
\hline \hline Attribute & Description & \\
\hline Individual Interpretation & $\begin{array}{l}\text { Capability to interpret individual } \\
\text { perceptions effectively } \\
\text { Interface Acceptance }\end{array}$ & $\begin{array}{l}\text { Capability to accept user interface } \\
\text { effectively } \\
\text { Capability to acquire knowledge process } \\
\text { effectively }\end{array}$ \\
\hline \hline
\end{tabular}

The classification of each readiness metric based on the corresponding attribute is presented below (Table III).

TABLE III: CATEGORIZATION OF READINESS METRICS

\begin{tabular}{ll}
\hline \hline Attribute & Metric \\
\hline Individual Interpretation & Answers Supplied \\
& Examples Provided \\
& Questions Given \\
Interface Acceptance & Information Memorized \\
& Layouts Recognized \\
& Representations Recalled \\
Knowledge Acquisition & Meanings Understood \\
& Problems Solved \\
& Reasons Explained \\
& Skills Integrated \\
\hline \hline
\end{tabular}

\section{B. Association between Readiness Measures}

The results of the association tests revealed that the Answers Supplied $(M=4.57, S D=.635)$, Examples Provided $(M=4.30, S D=.806)$ and Questions Given Correctly $(M=$ $4.22, S D=.909)$ metrics contribute towards the Individual Interpretation attribute in assessing the readiness of handheld application usage, where $p<.001$. In contrast, the Information Memorized $(M=4.37, S D=.804)$, Layouts Recognized $(M=4.28, S D=.742)$ and Representations Recalled $(M=4.30, S D=.778)$ metrics were found to contribute towards the Interface Acceptance readiness attribute $(p<.001)$.

The Meanings Understood $(M=4.35, S D=.771)$, Problems Solved $(M=4.42, S D=.777)$, Reasons Explained $(M=4.17, S D=.871)$ and Skills Integrated $(M=4.37, S D$ $=.788)$ metrics were found to contribute towards the Knowledge Acquisition readiness attribute $(p<.001)$. Finally, the association tests revealed the Individual Interpretation $(M$ $=4.38, S D=.690)$, Interface Acceptance $(M=4.37, S D$ 
$=.746)$ and Knowledge Acquisition $(M=4.45, S D=.650)$ attributes to all contribute towards measuring the readiness of handheld application usage $(p<.001)$.

As a result, a total of thirteen readiness measures (i.e., the abovementioned ten readiness metrics categorized into the three readiness attributes) were identified as significantly contributing towards the assessment of handheld application usage readiness. The results of the association tests for each readiness metric are presented in Table IV, and those for each readiness attribute in Table $\mathrm{V}$.

TABLE IV: RESUlts OF READINESS METRIC ASSOCIATION TESTS

\begin{tabular}{lcc}
\hline \hline Metric & Mean $(\mathrm{M})$ & Std.Dev. $(S D)$ \\
\hline Answers Supplied & 4.57 & .635 \\
Examples Provided & 4.30 & .806 \\
Information Memorized & 4.37 & .804 \\
Layouts Recognized & 4.28 & .742 \\
Meanings Understood & 4.35 & .771 \\
Problems Solved & 4.42 & .777 \\
Questions Given & 4.22 & .909 \\
Reasons Explained & 4.17 & .871 \\
Representations Recalled & 4.30 & .778 \\
Skills Integrated & 4.37 & .778 \\
\hline \hline
\end{tabular}

TABLE V: RESULTS OF READINESS ATTRIBUTE ASSOCIATION TESTS

\begin{tabular}{lcc}
\hline \hline Attribute & Mean $(\mathrm{M})$ & Std.Dev. $(S D)$ \\
\hline Individual Interpretation & 4.83 & .609 \\
Interface Acceptance & 4.37 & .746 \\
Knowledge Acquisition & 4.45 & .650 \\
\hline \hline
\end{tabular}

\section{Relationship between Readiness Measures}

The relationship test revealed a positive linear correlation between the respective contributions of the Answers Supplied, Examples Provided and Questions Given metrics towards the Individual Interpretation attribute $(p<.001)$. A similar positive relationship was also found between the metrics Information Memorized, Layouts Recognized and Representations Recalled towards the Interface Acceptance attribute $(p<.001)$.

The Meanings Understood, Problems Solved, Reasons Explained and Skills Integrated metrics were also found to exhibit a positive linear relationship in terms of their contribution towards the attribute Knowledge Acquisition ( $p$ $<.001)$. Finally, the relationship test indicated a positive correlation between the Individual Interpretation, Interface Acceptance and Knowledge Acquisition attributes towards measuring the readiness of handheld application usage ( $p$ $<.001)$.

Based on the above results, all ten readiness metrics were identified as having a positive linear relationship towards their respective usage readiness attributes. All three readiness attributes were also identified as having a similarly positive linear relationship in assessing handheld application usage readiness.

The relationship tests revealed that the Answers Supplied, Examples Provided and Questions Given metrics were all weighted towards the Individual Interpretation attribute with a value higher than .5 at $\omega=.553, \omega=.579$ and $\omega=.622$, respectively. The Meanings Understood $(\omega=.564)$, Problems Solved $(\omega=.527)$ and Skills Integrated $(\omega=.580)$ metrics were similarly weighted higher than .5 towards the Knowledge Acquisition attribute, with only the Reasons Explained $(\omega=.463)$ metric being below .5 .
In contrast, the Information Memorized $(\omega=.388)$, Layouts Recognized ( $\omega=.309)$ and Representations Recalled $(\omega=.442)$ metrics were found to contribute towards the Interface Acceptance attribute with a weight of less than .5. Finally, the association tests determined that the Individual Interpretation $(\omega=.395)$, Interface Acceptance $(\omega$ $=.454)$ and Knowledge Acquisition $(\omega=.483)$ attributes contribute to the measurement of handheld application usage readiness with a relationship weight value of less than .5 .

In summary, only six readiness metrics were identified as having a high relationship weight value (i.e., over .5) towards their corresponding readiness attributes, with the remaining four readiness metrics associated with a weight value lower than .5. In addition, all three readiness attributes were found to exhibit a low relationship weight value in assessing the readiness of handheld application usage.

According to the obtained relationship weight results, a high relationship strength exists between the Answers Supplied, Examples Provided and Questions Given metrics towards the Individual Interpretation attribute $(p<.001)$. In contrast, the recorded coefficient values of the Information Memorized, Layouts Recognized and Representations Recalled metrics are only moderate in strength towards the Interface Acceptance attribute $(p<.001)$.

Whereas the Reasons Explained metric was found to have a moderately strong relationship with the Knowledge Acquisition attribute $(p<.001)$, the Meanings Understood, Problems Solved and Skills Integrated metrics exhibited a high relationship strength $(p<.001)$. Finally, the relationship test revealed that the Individual Interpretation, Interface Acceptance and Knowledge Acquisition attributes all possess moderate relationship strength towards measuring the readiness of handheld application usage $(p<.001)$.

In conclusion, six readiness measures were identified as having high relationship strength and the remaining seven as having moderate relationship strength in terms of handheld application usage readiness assessment. None of the readiness measures were found to have a low relationship strength.

The results of the relationship test for each readiness metric towards their corresponding readiness attributes are depicted in Table VI. The results of the relationship test for each readiness attribute towards assessing the readiness of handheld application usage are presented in Table VII.

TABLE VI: RESULTS OF READINESS METRIC RELATIONSHIP TESTS

\begin{tabular}{lcc}
\hline \hline Metric & Weight $(W)$ & Strength $(S)$ \\
\hline Answers Supplied & .553 & High \\
Examples Provided & .579 & High \\
Information Memorized & .388 & Moderate \\
Layouts Recognized & .309 & Moderate \\
Meanings Understood & .564 & High \\
Problems Solved & .527 & High \\
Questions Given & .622 & High \\
Reasons Explained & .463 & Moderate \\
Representations Recalled & .442 & Moderate \\
Skills Integrated & .580 & High \\
\hline \hline
\end{tabular}

TABLE VII: RESULTS OF READINESS ATTRIBUTE RELATIONSHIP TESTS

\begin{tabular}{lcc}
\hline \hline Attribute & Weight $(W)$ & Strength $(S)$ \\
\hline Individual Interpretation & .395 & Moderate \\
Interface Acceptance & .454 & Moderate \\
Knowledge Acquisition & .483 & Moderate \\
\hline \hline
\end{tabular}




\section{Rank Order of Readiness Measures}

Combined analysis of the results of the association and relationship tests revealed that the Answers Supplied (with an association rank point score, ARP $=1$ and relationship rank point score, RRP = 5), Examples Provided $(A R P=6, R R P=$ 3 ) and Questions Given (ARP = 9, RRP = 1) metrics, which together contribute towards the Individual Interpretation attribute, were ranked second, fourth and sixth with mean joint point (MJP) scores of 3, 4.5 and 5, respectively, in assessing the readiness of handheld application usage. The Information Memorized $(\mathrm{ARP}=3, \mathrm{RRP}=9, \mathrm{MJP}=6)$, Layouts Recognized $(\mathrm{ARP}=8, \mathrm{RRP}=10, \mathrm{MJP}=9)$ and Representations Recalled $(\mathrm{ARP}=6, \mathrm{RRP}=8, \mathrm{MJP}=7$ ) metrics, which contribute towards the Interface Acceptance attribute, rank seventh, tenth and eighth, respectively.

Regarding the three metrics contributing towards the Knowledge Acquisition attribute, Meanings Understood ranked fourth $(\mathrm{ARP}=5, \mathrm{RRP}=4, \mathrm{MJP}=4.5)$, Problems Solved third $(\mathrm{ARP}=2, \mathrm{RRP}=6, \mathrm{MJP}=4)$, Skills Integrated first $(\mathrm{ARP}=3, \mathrm{RRP}=2, \mathrm{MJP}=2.5)$, and Reasons Explained ninth $(\mathrm{ARP}=10, \mathrm{RRP}=7, \mathrm{MJP}=8.5)$. Finally, the attributes Knowledge Acquisition $(\mathrm{ARP}=2, \mathrm{RRP}=1, \mathrm{MJP}=1.5)$, Individual Interpretation $(\mathrm{ARP}=1, \mathrm{RRP}=3, \mathrm{MJP}=2)$ and Interface Acceptance $(\mathrm{ARP}=3, \mathrm{RRP}=2, \mathrm{MJP}=2.5)$ ranked first, second and third, respectively, in the assessment of handheld application usage readiness.

The rank of each readiness metric towards its corresponding attribute in assessing the readiness of handheld application usage is depicted in Table VIII, with that of each readiness attribute shown in Table IX.

\section{REAdinESS MEASUREMENT FrAMEWORK (RMF)}

In order to structurally present the identified readiness measures, a conceptual framework entitled the Readiness Measurement Framework (RMF) was designed. This framework brings together all thirteen readiness measures (i.e. the ten readiness metrics and three readiness attributes) and assigns them to different hierarchy levels. The rank orders of the ten readiness metrics and three readiness attributes towards the assessment of handheld application usage readiness are presented in Table $\mathrm{X}$ and Table XI, respectively.

TABLE VIII: RANK ORDER OF READINESS METRICS

\begin{tabular}{lcc}
\hline \hline Metric & Mean Joint Point (MJP) & Rank Order \\
\hline Answers Supplied & $(1+5) / 2=3$ & 2 \\
Examples Provided & $(6+3) / 2=4.5$ & 4 \\
Information Memorized & $(3+9) / 2=6$ & 7 \\
Layouts Recognized & $(8+10) / 2=9$ & 10 \\
Meanings Understood & $(5+4) / 2=4.5$ & 4 \\
Problems Solved & $(2+6) / 2=4$ & 3 \\
Questions Given & $(9+1) / 2=5$ & 6 \\
Reasons Explained & $(10+7) / 2=8.5$ & 9 \\
Representations Recalled & $(6+8) / 2=7$ & 8 \\
Skills Integrated & $(3+2) / 2=2.5$ & 1 \\
\hline \hline
\end{tabular}

TABLE IX: RANK ORDER OF READINESS ATTRIBUTES

\begin{tabular}{lcc}
\hline \hline Attribute & Mean Joint Point (MJP) & Rank Order \\
\hline Individual Interpretation & $(1+3) / 2=2$ & 2 \\
Interface Acceptance & $(3+2) / 2=2.5$ & 3 \\
Knowledge Acquisition & $(2+1) / 2=1.5$ & 1 \\
\hline \hline
\end{tabular}

TABLE X: RANK ORDER OF READINESS METRICS TOWARDS THEIR CORRESPONDING ATTRIBUTES

\begin{tabular}{lc}
\hline \hline Metric $\rightarrow$ Attribute & Rank Order \\
\hline Skills Integrated $\rightarrow$ Knowledge Acquisition & 1 \\
Answers Supplied $\rightarrow$ Individual Interpretation & 2 \\
Problems Solved $\rightarrow$ Knowledge Acquisition & 3 \\
Meanings Understood $\rightarrow$ Knowledge Acquisition & 4 \\
Examples Provided $\rightarrow$ Individual Interpretation & 4 \\
Questions Given $\rightarrow$ Individual Interpretation & 6 \\
Information Memorized $\rightarrow$ Interface Acceptance & 7 \\
Representations Recalled $\rightarrow$ Interface Acceptance & 8 \\
Reasons Explained $\rightarrow$ Knowledge Acquisition & 9 \\
Layouts Recognized $\rightarrow$ Interface Acceptance & 10 \\
\hline \hline
\end{tabular}

TABLE XI: RANK ORDER OF READINESS ATTRIBUTES TOWARDS ASSESSING THE READINESS OF HANDHELD APPLICATION USAGE

\begin{tabular}{lc}
\hline \hline Attribute $\rightarrow$ Readiness & Rank Order \\
\hline Knowledge Acquisition $\rightarrow$ Readiness & 1 \\
Individual Interpretation $\rightarrow$ Readiness & 2 \\
Interface Acceptance $\rightarrow$ Readiness & 3 \\
\hline \hline
\end{tabular}

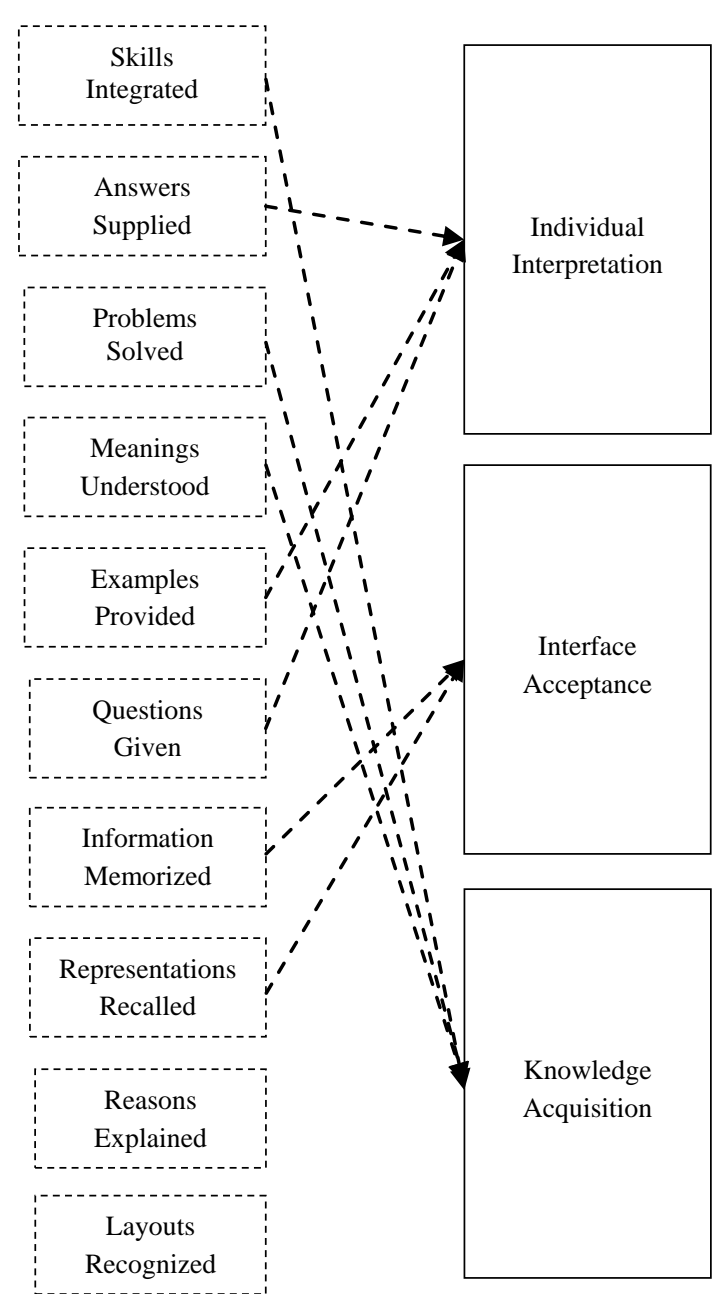

Fig. 1. Mapping of readiness metrics towards their corresponding attribute.

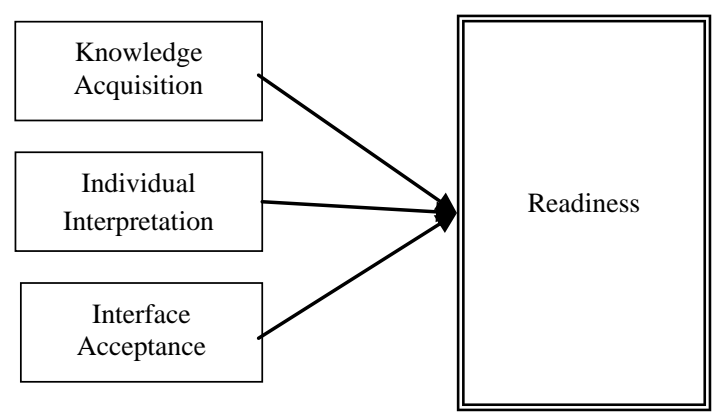

Fig. 2. Mapping of readiness attributes towards readiness assessment. 


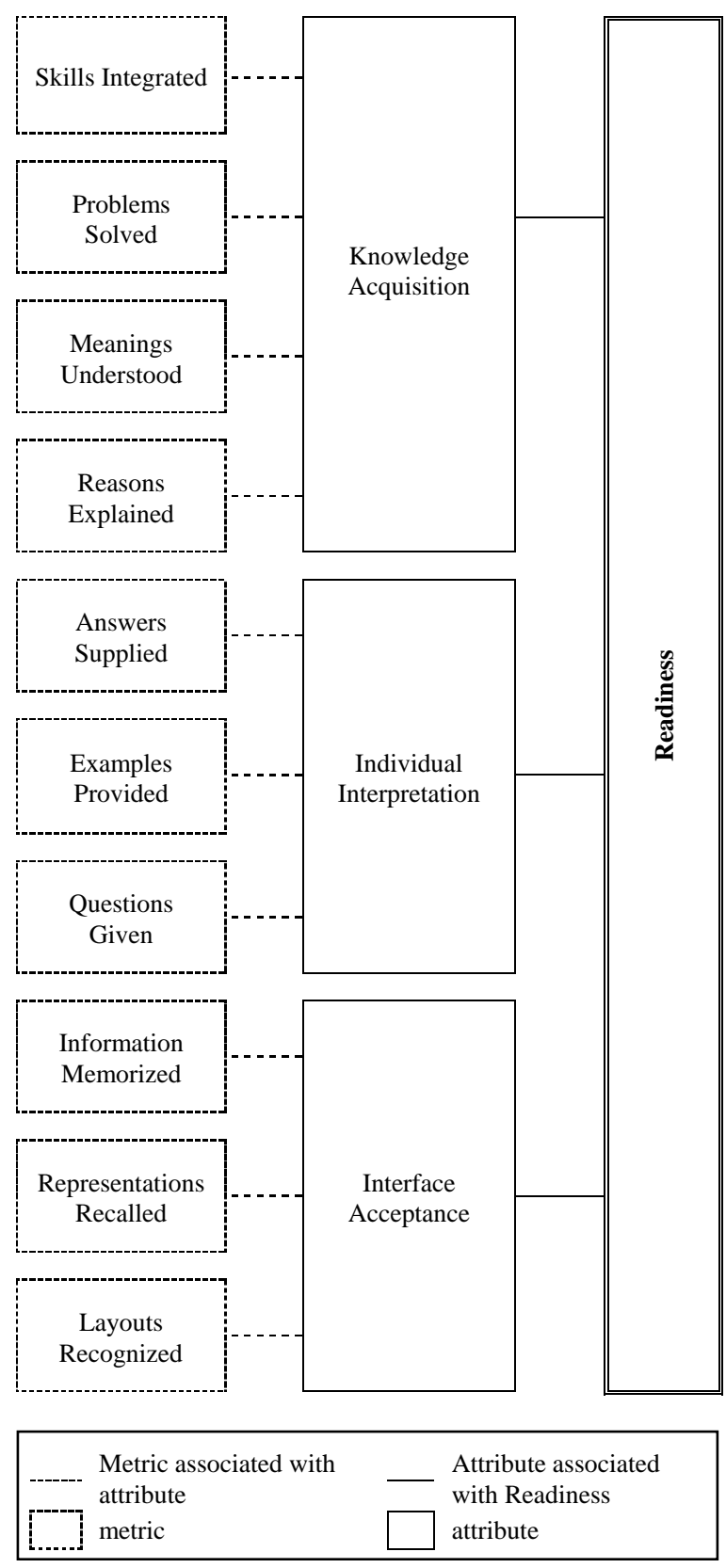

Fig. 3. Readiness measurement framework (RMF).

Fig. 1 shows the mapping of each readiness metric towards their corresponding attribute based on the obtained association and relationship results. The association and relationship of these three readiness attributes towards the assessment of handheld application usage readiness is then presented in Fig. 2.

The results of the ranking, association, and relationship tests carried out on the ten readiness metrics and three readiness attributes thus produced the conceptual Readiness Measurement Framework (RMF) shown in Fig. 3.

\section{CONCLUSION}

The emergence of new computing technologies poses fresh challenges to established practices of assessing the readiness of handheld application usage. Further research is thus required in order to improve both application performance and user satisfaction. The present study was therefore conducted mainly to identify measures with which to assess handheld application usage readiness.
The obtained results not only reveal the readiness relationship factors between handheld users and applications, but also provide a better understanding of the importance of these factors towards assessing handheld application usage readiness. In addition, these measures are valuable as an alternative design method or technique with which to ensure the readiness of handheld applications. In the future, it is recommended that these findings are used to establish a concrete evaluation technique as well as to develop a model for the assessment and measurement of handheld application usage readiness.

\section{ACKNOWLEDGMENT}

This study was a part of a large-scale research project focusing on the development of a Handheld Applications Usability Measurement Model (HApps-UMM) aimed at the mathematic measurement of handheld application usability. Thanks go to Professor Dato' Dr. Aziz Deraman for his considerable help and support throughout this work.

\section{REFERENCES}

[1] J. Roschelle and R. Pea, "A walk on the WILD side: How wireless handhelds may change CSCL," International Journal of Cognition and Technology, vol. 1, no. 1, pp. 145-168, 2002.

[2] S. Weiss, Handheld usability West Sussex, John Wiley \& Sons, 2002.

[3] D. Quan, "Designing end user information environments based on semi-structured data models," Ph.D. Thesis, MIT, USA, 2003.

[4] M. Finn and N. Vandenham, "The handheld classroom: Educational implications of mobile computing," Australian Journal of Emerging Technologies and Society, vol. 2, no. 1, 2004.

[5] IDC, "Five segments will lead software out of the complexity crisis," Doc \#VWP000148, 2002.

[6] M. Chae and J. Kim, "Do size and structure matter to mobile users? An empirical study of the effects of screen size, information structure, and task complexity on user activities with standard web phones," Behaviour \& Information Technology, vol. 23, no. 3, pp. 165-181, 2004.

[7] IDC, "The battle at hand: The smart handheld devices market forecast and analysis 2000-2004," 2000.

[8] S. Brewster and R. Murray, "Presenting dynamic information on mobile computers," Personal and Ubiquitous Computing, vol. 4, pp. 209-212, 2000.

[9] L. Kim and M. J. Albers, "Web design issues when searching for information in a small screen display," in Proc. the 19th Annual International Conference on Computer Documentation, Sante Fe, New Mexico, USA, 2001.

[10] L. Kim and M. J. Albers, "Presenting Information in the small-screen interface: Effects of table formatting," IEEE Transactions in Documentation, 2003.

[11] J. Tang, N. Yankelovich, B. Begole, K. M. Van, F. Li, and J. Bhalodia, "ConNexus to awarenex: Extending awareness to mobile users," in Proc. CHI2001, Seattle, WA, USA, ACM, 2001.

[12] S. Brewster, "Overcoming the Lack of Screen Space on Mobile Computers," Personal and Ubiquitous Computing, vol. 6, pp. 188-205, 2002.

[13] M. Pierce, C. Youn, and G. Fox, "Interacting data services for distributed earthquake modeling," in Proc. the International Conference on Computational Science, 2003, pp. 863-872.

[14] D. Pownell, and G. D. Bailey, "The next small thing: Handheld computing for educational leaders," Learning and Leading with Technology, vol. 27, no. 8, pp. 59-60, 2000.

[15] K. P. Yee, "Peephole displays: Pen interaction on spatially aware handheld computers," in Proc. the SIGCHI Conference on Human Factors in Computing Systems, 2003, pp. 1-8.

[16] P. Wangemann, N. Lewis, and D. A. Squires, "Portable technology comes of age," T.H.E. Journal, vol. 31, no. 4, pp. 26-32, 2003.

[17] V. Venkatesh, M. G. Morris, G. B. Davis, and F. D. Davis, "User acceptance of information technology: Toward a unified view," MIS Quarterly, vol. 27, no. 3, pp. 425-478, 2003.

[18] M. Velez, M. M. Tremaine, A. Sarcevic, B. Dorohonceanu, A. Krebs et al., "Who's in charge here? Communicating across unequal computer 
platforms," ACM Trans. Computer-Human Interaction, vol. 11, no. 4 , pp. 407-444, 2004

[19] P. Zhang, J. Carey, D. Te'eni, and M. Tremaine, "Integrating human-computer interaction development in SDLC: A methodology," Americas Conference on Information Systems, New York, 2004

[20] P. Zhang, J. Carey, D. Te'eni, and M. Tremaine, "Integrating human-computer interaction development into the systems development life cycle: A methodology," Communications of the Association for Information Systems, vol. 15, pp. 512-543, 2005.

[21] F. D. Davis, "Perceived Usefulness, Perceived Ease of Use, and User Acceptance of Information Technology," MIS Quarterly, vol. 13, no. 3, pp. 319-340, 1989.

[22] F. D. Davis, R. P. Bagozzi, and P. R. Warshaw, "User acceptance of computer technology: A comparison of two theoretical models," Management Science, vol. 35, pp. 982-1003, 1989.

[23] G. D. Abowd and R. Beale, "Users, systems and interfaces: A unifying framework for interaction," Human Computer Interaction (HCI'91): People and Computers, vol. 6, pp. 73-87, 1991.

[24] [24] S. R. Chidamber, and C. F. Kemerer, "A metrics suite for object oriented design," IEEE Transactions on Software Engineering, vol. 20 no. 6, pp. $476-493,1994$.

[25] CMMI. "Capability maturity model integration for development, version 1.2," Technical Report CMU/SEI-2006-TR-008, Carnegie Mellon University Software Engineering Institute, 2006.

[26] E. Nemeth, R. Lakner, K. M. Hangos, and I. T. Cameron, "Prediction-based diagnosis and loss prevention using qualitative multi-scale models," Information Sciences, vol. 177, pp. 1916-1930, 2007.

[27] A. Asthana and J. Olivieri, "Quantifying software reliability and readiness," IEEE International Workshop Technical Committee on Communications Quality and Reliability (CQR 2009), 2009, pp. 1-6.

[28] Q. Tong-Hyperlink. (2009). [Online]. 179. pp. 430-445. Available: http://www.sciencedirect.com/science/article/pii/S0020025508004222

[29] P. M. Anne, K. Vijay, and V. Ramesh, "From the Web to the Wireless Web: Technology Readiness and Usability," in Proc. the 38th Annual Hawaii International Conference on System Sciences (HICSS'05), 2005, p. 32.
[30] S. AlShaali, "On the usability of mobile commerce," International Journal of Mobile Communications, vol. 4, no. 4, pp. 436-458, 2006.

[31] Z. Qu and J. Sun, "Adaptive mobile web interface: user readiness in context," International Journal of Mobile Communications, vol. 10, no. 2, pp. 132-149, 2012.

[32] S. Khan, M. N. "A Readiness Model for Software Development Outsourcing Vendors," IEEE International Conference on Global Software Engineering (ICGSE 2008), 2008, pp. 273-277.

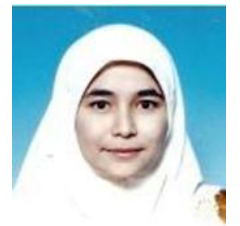

Amalina F. A. Fadzlah obtained a bachelor of information technology degree in networking (with honors) in 1998 and a master of science in information technology degree in 2002 from the Faculty of Information Technology, Northern University of Malaysia. She also obtained a doctor of philosophy degree in computer science in 2010 from the Faculty of Technology and Information Science, National

University of Malaysia.

She is currently a senior lecturer at the Department of Computer Science, Faculty of Defense Science and Technology, and a Coordinator at the eLearning Unit, Center for Academic Development, National Defense University of Malaysia. She has thirteen years of extensive experience in teaching and mentoring students, and eleven years of comprehensive experience in the research and development of handheld - based software application systems, with an interest in the field of Software Engineering specializing in software quality, software certification, software management, and human computer interaction. Her current research interest relates to the usability of mobile learning application systems and in particular to the design, development and implementation of Smart Maths Solution, a mobile mathematics learning application system, as well as Comic-Science, a comic-styled mobile science learning application for primary level students.

Dr. Fadzlah is a senior member of the International Association of Computer Science and Information Technology (IACSIT) and a Member of the Society of Digital Information and Wireless Communications (SDIWC), the Malaysian Information Technology Society (MITS), and the Mobile Learning Association of Malaysia. 